\title{
Hemodiyaliz Tedavisi Alan Hastalarda Düşme Riskinin Belirlenmesi
}

\section{Determining the Risk of Falling in Patients Receiving}

\section{Hemodialysis Treatment}

\author{
Emine KARAMAN ${ }^{1}$, Şengül ÖZDEMİR ${ }^{2}$, Asiye AKYOL $^{3}$
}

${ }^{I}$ Dr. Öğr. Üyesi- Ege Üniversitesi Hemşirelik Fakültesi, $\dot{I}_{c ̧}$ Hastalıkları Hemşireliği AD, İzmir, Türkiye

${ }^{2}$ Hemşire- Özel Buca Dmed Diyaliz Merkezi, İzmir, Türkiye

${ }^{3}$ Prof. Dr.- Ege Üniversitesi Hemşirelik Fakültesi, İç Hastalıkları Hemşireliği AD, İzmir, Türkiye

Geliș Tarihi / Received :

04 Ağustos 2020

\section{Kabul Tarihi / Accepted:}

22 Eylül 2020

\section{İletişim yazarı \\ Correspondence author}

Emine KARAMAN

E-posta: emine.karaman@ege.edu.tr

\section{ORCID:}

Emine KARAMAN

https://orcid.org/0000-0002-9358-2593

\section{Şengül ÖZDEMIR}

https://orcid.org/0000-0002-9320-4912

\section{Asiye AKYOL}

https://orcid.org/0000-0003-1018-4715

\section{Özet}

Amaç: Bu çalışma hemodiyaliz tedavisi alan hastalarda düşme riskinin belirlenmesi amacıyla yapılmıştır.

Method: Tanımlayıcı ve kesitsel tipte olan çalışma özel bir diyaliz merkezinde gerçekleştirilmiştir. Örneklemi, çalışmanın yapıldığı diyaliz merkezinde MartAğustos 2019 tarihleri arasında hemodiyaliz tedavisi alan 331 gönüllü hasta oluşturmuştur. Veriler, Birey Tanıtım Formu, İtaki Düşme Riski Ölçeği ve Morse Düşme Riski Ölçeği kullanılarak toplanmıștır. Verilerin analizinde yüzdelik, ortalama, standart sapma, t testi, ki-kare ve Kruskal Wallis analizi kullanılmıştır.

Bulgular: Çalışmaya dahil edilen hastaların yaş ortalaması $67.41 \pm 12.64$ yıl olup, ortalama hemodiyaliz tedavi alma süresi $56.53 \pm 52.68$ aydır. Hastaların $\% 53.2$ 'si erkek, \%88.5'i evlidir. Hastaların \%10.3'ü sigara, \%8.5'i alkol kullanmaktadır. Hemodiyaliz tedavisi alan hastaların \%87.9'unun bu tedavi dışında ek bir tedavi daha aldığı ve yine hastaların \%99.1'inin kronik böbrek yetmezliği dışında ek bir hastalığının olduğu bulunmuştur. Hastaların \%50.8'inin İtaki Düşme Riski Ölçeği'ne göre düşük risk grubunda, Morse Düşme Riski Ölçeği'ne göre hastaların \%70.4'ünün düşük risk grubunda olduğu belirlenmiştir. İtaki Düşme Riski Ölçeği'ne göre örneklemi oluşturan hastaların \%49.2'sinin yüksek düşme riskine sahip olduğu ve bu yüksek risk grubundaki hastaların \%52.8'ini kadınların oluşturduğu görülmüştür. Morse Düşme Riski Ölçeği’ne göre orta ve yüksek risk grubundaki bireylerin çoğunu kadınların oluşturduğu görülürken, düşük risk grubunda daha çok erkeklerin olduğu görülmektedir. Yapılan ki-kare analizi sonrasında hem İtaki Düşme Riski Ölçeği $(\mathrm{p}=0.03)$ hem de Morse Düşme Riski Ölçeği'nde $(\mathrm{p}=0.006)$ kadınların erkeklere göre daha yüksek düşme riskine sahip oldukları belirlenmiştir.

Sonuç: Hemodiyaliz tedavisi alan hastaların yaklaşık yarısında düşme riski yüksek olup; kadınların erkeklere göre daha yüksek düşme riskine sahip olduğu görülmüştür. $\mathrm{Bu}$ nedenle, kliniklerde düşme risk belirleme araçlarını etkin kullanmak riskli hastaları belirlemede önemlidir.

Anahtar Kelimeler: Düşme riski, Hasta, Hemodiyaliz, Hemşirelik bakımı. 


\begin{abstract}
Objective: This study was conducted to determine the risk of falls in patients receiving hemodialysis treatment.

Method: The descriptive and cross-sectional study was carried out in a private dialysis center. The sample consisted of 331 volunteer patients who received hemodialysis treatment between March and August 2019 from the dialysis center where the study was conducted. The data were collected using the Individual Information Form, the Itaki Falling Risk Scale, and the Morse Falling Risk Scale. Percentage, mean, standard deviation, t-test, chi-square, and Kruskal Wallis analysis were used in the analysis of the data.
\end{abstract}

Results: The average age of the patients included in the study was $67.41 \pm 12.64$ years, and the mean duration of hemodialysis treatment was $56.53 \pm 52.68$ months. $53.2 \%$ of the patients are male, $88.5 \%$ are married. $10.3 \%$ of patients use cigarettes and $8.5 \%$ use alcohol. It was found that $87.9 \%$ of patients receiving hemodialysis treatment received an additional treatment other than this treatment, and again $99.1 \%$ of the patients had an additional disease other than chronic renal failure. It was determined that $50.8 \%$ of the patients were in the low-risk group according to the fall risk scale, and $70.4 \%$ of the patients were in the low-risk group according to the Morse Fall Risk Scale. It was observed that $49.2 \%$ of the patients who made the sample according to the Itaki Falling Risk Scale had a high risk of falling and $52.8 \%$ of the patients in this high-risk group were women. According to the Morse Fall Risk Scale, most of the individuals in the medium and high-risk groups are women, while it is seen that there are more men in the low-risk group. After the chi-square analysis, it was determined that women had a higher risk of falling compared to men in both the risk of falling in itas scale ( $p=$ $0.03)$ and morse risk of falling $(p=0.006)$.

Conclusion: The risk of falling is high in approximately half of the patients receiving hemodialysis treatment; women were found to have a higher risk of falling than men. For this reason, it is important to use the fall risk determination tools effectively in determining the risk patients.

Keywords: Risk of falling, Patient, Hemodialysis, Nursing care.

\section{GíRIS}

Tüm dünyada ve ülkemizde hemodiyaliz (HD) hastalarının insidans ve prevalansı trajik olarak artmaktadır (1). Hemodiyaliz hastalarında mortaliteyi ve yaşam kalitesini etkileyen birçok komorbid etken vardır $(2,3)$. Bu etkenler arasinda anksiyete, depresyon, yorgunluk ve düşme yer almaktadır (4-6). Düşmeler de HD hastalarında önemli düzeyde negatif sonuçları olan bir durumdur $(5,6)$. Düşmelere odaklanan makale sayısının son yıllarda artış göstermesine karşın, HD hastalarında düşme ve risk faktörlerini inceleyen az sayıda çalışmaya ulaşılabilmiştir (68).

Dünya Sağl1k Örgütü'ne (DSÖ) göre, düşme, kişinin dikkatsizlik ya da kaza nedeni ile yerde ya da kendisinden daha alt bir düzeyde uzanır duruma gelmesi olarak tanımlanmıştır (9). Düşmeler, hasta güvenliğini tehdit eden durumların başında gelmesinin yanı sıra (10) sağlık bakım maliyetinde de artışa neden olması bakımından da önemlidir (11-13). Sağlık Kuruluşları Akreditasyonu Ortak Komisyonu (JCI) Amerika Birleşik Devletleri (ABD)'ndeki hastanelerde her y1l yüz binlerce hastanın düştüğünü, bunların da \%30-50 oranında yaralanma ile sonuçlandığını, yaralanan bireylerin gerek ek tedavi gereksinimleri gerekse hastanede kalış süresinin uzamasının maliyeti olumsuz etkilediğini belirtmiştir (10). Düşmeler ve düşmelere bağlı görülen kırık ve yumuşak doku yaralanmaları kronik böbrek yetmezliği (KBY) olan bireylerde ciddi mortalite ve morbiditeye neden olmaktadır $(14,15)$.

Düşme olasıllı̆̆ bireyler için her zaman var olmasına karşın, bazı hastalıklarda ve tedavi 
şekillerinde daha fazla görülebilmektedir (16). Özellikle KBY gibi tüm organ ve sistemleri etkileyen hastalıklarda ve HD gibi tedavi süreçlerinde fonksiyonel kayıplar, fiziksel aktivite kapasitesindeki azalmalarla birlikte düşme riskindeki artış dikkat çekicidir (17). Özellikle, KBY ve HD tedavisi ile birlikte alınan ilaçlar, ortostatik hipotansiyon, D vitamini eksikliği, hematolojik bozukluklar ve ileri yaş gibi değişkenlerin düşme riskini arttıracağı belirtilmektedir (18). Düşmeye bağlı yaralanmaların bireylere ve kurumlara olan yükünü azaltmak için HD tedavisi alan bireylerin düşme risklerinin değerlendirilmesi ve uygun önlemlerin alınması büyük önem taşımaktadır. $\mathrm{Bu}$ doğrultuda çalışmanın amacı HD tedavisi alan kronik böbrek yetmezliği olan bireylerde düşme riskinin belirlenmesidir.

\section{GEREÇ VE YÖNTEM}

\section{Araştırmanın Amacı ve Tipi}

Tanımlayıcı ve kesitsel tipte yapılan bu araştırma, HD tedavisi alan bireylerde düşme riskinin belirlenmesi amacıyla yapılmıştır.

\section{Araştırma Evreni ve Örneklemi}

Araştırma evrenini, özel bir diyaliz merkezinde HD tedavisi alan hastalar oluşturmuştur. Örneklem seçimine gidilmemiş olup, evreni oluşturan 331 hastanın tamamına ulaşılması hedeflenmiştir. Mart-Ağustos 2019 tarihleri arasında çalışmanın yapıldığ 1 diyaliz merkezinde HD tedavisi alan, çalı̧̧maya katılmaya gönüllü olan 331 hasta örneklemi oluşturmuştur.

\section{Veri Toplama Araçları}

Araştırmanın verileri HD merkezinde diyaliz işlemi sırasında, ortalama 10-15 dakikada, araştırmacılar tarafından yüz yüze görüşme tekniği ile "Birey Tanıtım Formu" ve "İtaki Düşme Riski Ölçeği” ve "Morse Düşme Riski Ölçeği” kullanılarak toplanmıştır. Bireylerin laboratuvar bulgularına hasta kayıtlarının incelenmesi ile ulaşı1mıştır.

Birey Tanıtım Formu: Araştırmacılar tarafindan oluşturulan bu formda hastaların sosyo-demografik özellikleri (yaşı, cinsiyeti, medeni durumu, gelir düzeyi, aile yapısı, eğitim durumu) ile sağlık-hastalık durumunu sorgulayan (sigara alkol kullanımı, HD süresi, ek tedavi varlığı, tedaviye uyumu, sıvı tüketimi, kolesterol değerleri, böbrek yetmezliğine yönelik komplikasyon varlı̆̆ı) toplam 23 soru bulunmaktadır.

İtaki Düşme Riski Ölçeği: Sağlıkta Kalite Standartlarında "Hasta Güvenliği” uygulamalarının bir parçası olan hasta düşmelerinin önlenmesi konusunda, ülkemize özgü bir ölçek olarak T.C. Sağlık Bakanlığ 1 tarafından geliştirilmiştir. Ölçek hasta düşmelerine neden olabilecek risk faktörlerini içerecek şekilde, toplam 19 risk faktöründen oluşmaktadır. Risk faktörleri majör ve minör olarak kategorize edilerek minör risk faktörlerine 1 puan, majör risk faktörlerine ise 5 puan verilmiştir. Risk faktörlerinin değerlendirilmesi sonucu elde edilen toplam puan üzerinden düşük ve yüksek olmak üzere iki risk düzeyi belirlenmiştir: 0-4 arası puanlar düşük risk, 5 ve üzeri puanlar yüksek risk olarak değerlendirilmektedir (19).

Morse Düşme Riski Ölçeği: Ölçek 1985 yılında Janice M. Morse tarafından geliştirilmiştir. Ölçek, düşme riskini tanılayan altı kriterden (düşme hikayesinin varlığı, ikincil tanı, mobilizasyon desteği, intravenöz yol varlığı ya da heparin kullanımı, yürüyüşs/transfer ve mental durum) oluşmaktadır. Ölçekten 25 'ten az puan alınd1ğında düşük risk, 25-50 arasında bir puan alınd1ğında orta risk, 51 ve üzeri puan alındığında yüksek risk olarak değerlendirilmektedir $(20,21)$. Ölçeğin Türkçe geçerlik güvenirliği YılmazDemir (2011) tarafından yapılmıştır (22).

\section{Araştırmanın Etik Yönü}

$\mathrm{Bu}$ araştırma Helsinki Deklarasyonu Prensipleri'ne uygun olarak yürütülmüştür. Araştırmanın yürütülebilmesi için bir üniversitenin Tıbbi Araştırmalar Etik Kurulu'ndan (03/05/2019-E.136663) etik izin, araştırmanın yapıldığ 1 kurumlardan kurum izni ve ölçek sahibinden ölçek kullanım izni alınmıştır. Araştırmaya katılan hastalardan bilgilendirilmiş yazılı onam alınmıştır.

\section{İstatistiksel Analiz}

Verilerin değerlendirilmesinde SPSS 22 paket programı kullanılmıştır. Veri toplama formla- 
rından elde edilen ordinal veriler aritmetik ortalama, standart sapma, minimum-maksimum degerlerle hesaplanmış, nominal veriler ise frekans ve yüzde olarak değerlendirilmiştir. Araştırmada bağımsız değişkenlerin ölçek toplam puan ortalamaları ile karşılaştııılmasında, verilerin normal dağılımı incelenmiştir. Verilerin analizinde yüzdelik, ortalama, standart sapma, t testi, ki-kare ve Kruskal Wallis analizi kullanılmıştır. Sonuçlar, $\% 95$ güven aralığında ve $p<0.05$ anlamlılık düzeyinde değerlendirilmiştir.

\section{BULGULAR}

Çalışmaya katılan bireylerin yaklaşık yarısı 65-79 yaş aralığında bulunmaktadır. Hastaların yaş ortalamas1 $67.41 \pm 12.64(\min 20-\max 91)$ y1ldır. Hastaların diyalize girme süreleri 1 ay ile 403 ay arasında değişmekte olup, ortalama $56.53 \pm 52.68$ aydır. Hastaların \%53.2'si erkek, \%88.5'i evlidir. Hastaların \%10.3'ünün sigara, \%8.5'inin alkol kullandığ 1 belirlenmiştir. Hastaların \%87.9'u HD tedavisi dışında ek bir tedavi alırken, \%99.1'i KBY dışında ek bir hastalığa sahiptir. Hastaların $\% 50.8$ 'i genel sağlık durumunu orta olarak değerlendirdiği, \%66.5'inin sedanter yaşam sürdüğü, \%47.7'sinde herhangi bir komplikasyon olmadığ 1 belirlenmiştir. Hastaların hemoglobin düzeyi ortalamas1 $11.22 \pm 1.40 \mathrm{mg} / \mathrm{dl}$, hematokrit ortalamas1 $\% 35.30 \pm 5.22$, yüksek yoğunluklu lipoprotein (high density lipoprotein=HDL) ortalamas1 $139 \pm 16.03 \mathrm{mg} / \mathrm{dL}$, düşük yoğunluklu lipoprotein (low density lipoprotein=LDL) ortalamas1 $116.93 \pm 41.46 \mathrm{mg} / \mathrm{dL}$, Trigliserid (TG) ortalamas1 $176.64 \pm 88.28 \mathrm{mg} / \mathrm{dL}$, total kolesterol $167.16 \pm$ $44.84 \mathrm{mg} / \mathrm{dL}$, sistolik kan basinc1 ortalamas1 $125.11 \pm 20.46 \mathrm{mmHg}$, diyastolik kan basıncı ortalamas1 68.88 \pm 14.18 mmHg'dir. Hastaların \%52.3'ü mevcut tedavisine uyumludur (Tablo 1,2).

Hastaların İtaki Düşme Riski Ölçeği'ne göre \%50.8'inin, Morse Düşme Riski Ölçeği'ne göre \%70.4'ünün düşük risk grubunda olduğu belirlenmiştir (Tablo 3). Örneklemi oluşturan hastaların \%49.2'si İtaki Düşme Riski Ölçeği'ne göre yüksek düşme riskine sahiptir. Yine bu ölçeğe göre erkeklerin düşük risk grubunda daha fazla oranda olduğu görülmüştür (Tablo 4). Morse Düşme Riski Ölçeği'ne göre kadınların orta ve yüksek risk grubunda daha fazla oranda yer aldığ 1 erkeklerin ise düşük risk grubunda daha fazla oranda yer aldığ 1 saptanmıştır (Tablo 5). Yapılan ki-kare analizi sonrasında İtaki Düşme Riski Ölçeği $(p=0.03)$ ve Morse Düşme Riski Ölçeği puan ortalamalarının $(\mathrm{p}=0.006)$ kadınlarda erkeklere göre daha yüksek olduğu saptanmıştır (Tablo $4,5)$. 
Tablo 1. Hastaların Tanıtıcı Özellikleri ( $\mathrm{n}=331)$

\begin{tabular}{|c|c|c|}
\hline Tanıtıcı Özellik & \multicolumn{2}{|c|}{$\mathbf{X} \pm \mathrm{SD}$} \\
\hline Yaş (yıl) & \multicolumn{2}{|c|}{$67.41 \pm 12.64(\min .20-\max .91)$} \\
\hline Diyalize girme süresi (ay) & \multicolumn{2}{|c|}{$56.53 \pm 52.68(\min .1-\max .403)$} \\
\hline & $\mathbf{n}$ & $\%$ \\
\hline $\begin{array}{l}\text { Yaş grupları } \\
20-64 \text { yaş } \\
65-79 \text { yaş } \\
80 \text { ve üzeri }\end{array}$ & $\begin{array}{c}113 \\
165 \\
53 \\
\end{array}$ & $\begin{array}{l}34.1 \\
49.9 \\
16.0\end{array}$ \\
\hline $\begin{array}{l}\text { Cinsiyet } \\
\text { Kadın } \\
\text { Erkek }\end{array}$ & $\begin{array}{l}155 \\
176\end{array}$ & $\begin{array}{l}46.8 \\
53.2 \\
\end{array}$ \\
\hline $\begin{array}{l}\text { Medeni durum } \\
\text { Evli } \\
\text { Bekar }\end{array}$ & $\begin{array}{c}293 \\
38 \\
\end{array}$ & $\begin{array}{l}88.5 \\
11.5 \\
\end{array}$ \\
\hline $\begin{array}{l}\text { Birlikte yaşadığı bireyler } \\
\text { Tek } \\
\text { Eş } \\
\text { Çocuklar } \\
\text { Eş ve çocuklar }\end{array}$ & $\begin{array}{c}58 \\
126 \\
58 \\
89\end{array}$ & $\begin{array}{l}17.5 \\
38.1 \\
17.5 \\
26.9\end{array}$ \\
\hline $\begin{array}{l}\text { Sigara kullanımı } \\
\text { Evet } \\
\text { Hayır }\end{array}$ & $\begin{array}{c}34 \\
297\end{array}$ & $\begin{array}{l}10.3 \\
89.7\end{array}$ \\
\hline $\begin{array}{l}\text { Alkol kullanımı } \\
\text { Evet } \\
\text { Hayır }\end{array}$ & $\begin{array}{c}29 \\
302 \\
\end{array}$ & $\begin{array}{c}8.8 \\
91.2 \\
\end{array}$ \\
\hline $\begin{array}{l}\text { HD tedavisi dışında ek tedavi alma } \\
\text { Evet } \\
\text { Hayır }\end{array}$ & $\begin{array}{c}291 \\
40 \\
\end{array}$ & $\begin{array}{l}87.9 \\
12.1 \\
\end{array}$ \\
\hline $\begin{array}{l}\text { KBY dışında ek hastalık varı̆̆ı } \\
\text { Evet } \\
\text { Hayır }\end{array}$ & $\begin{array}{c}291 \\
40\end{array}$ & $\begin{array}{l}87.9 \\
12.1\end{array}$ \\
\hline $\begin{array}{l}\text { Kendi genel sağlık değerlendirmesi } \\
\text { İyi } \\
\text { Orta } \\
\text { Kötü }\end{array}$ & $\begin{array}{c}126 \\
168 \\
37\end{array}$ & $\begin{array}{l}38.1 \\
50.8 \\
11.2\end{array}$ \\
\hline $\begin{array}{l}\text { Fiziksel aktivite düzeyi } \\
\text { Sedanter } \\
\text { Düzenli spor } \\
\text { Haftada } 1 \text { den az spor }\end{array}$ & $\begin{array}{c}220 \\
37 \\
77\end{array}$ & $\begin{array}{l}66.5 \\
10.3 \\
23.3\end{array}$ \\
\hline $\begin{array}{l}\text { Komplikasyon varlığı } \\
\text { Yok } \\
\text { Akut } \\
\text { Kronik }\end{array}$ & $\begin{array}{c}158 \\
34 \\
139\end{array}$ & $\begin{array}{l}47.7 \\
10.3 \\
42.0\end{array}$ \\
\hline
\end{tabular}


Tablo 2. Hastaların Laboratuvar Değerleri $(n=331)$

\begin{tabular}{|l|c|}
\hline Laboratuvar bulguları & X \pm SD \\
\hline Hemoglobin düzeyi (gr/dL) & $11.22 \pm 1.40$ \\
\hline Hematokrit düzeyi (\%) & $35.30 \pm 5.22$ \\
\hline HDL düzeyi (mg/dL) & $139 \pm 16.03$ \\
\hline LDL düzeyi (mg/dL) & $116.93 \pm 41.46$ \\
\hline TG düzeyi (mg/dL) & $176.64 \pm 88.28$ \\
\hline Total kolesterol düzeyi (mg/dL) & $167.16 \pm 44.84$ \\
\hline Sistolik kan basıncı $(\mathrm{mmHg})$ & $125.11 \pm 20.46$ \\
\hline Diyastolik kan basınc1 $(\mathrm{mmHg})$ & $68.88 \pm 14.18$ \\
\hline
\end{tabular}

Tablo 3. Hastaların Düşme Riski Ölçeklerine Göre Sonuçları

\begin{tabular}{|l|c|c|}
\hline Düşme Ölçekleri & n & \% \\
\hline İtaki Düşme Riski Ölçeği & & 50.8 \\
Düşük & 168 & 49.2 \\
Yüksek & 163 & \\
\hline Morse Düşme Riski Ölçeği & & 70.4 \\
Düşük & 233 & 26.3 \\
Orta & 87 & 3.3 \\
Yüksek & 11 & \\
\hline
\end{tabular}

Tablo 4. Hastaların Bazı Değişkenlere Göre İtaki Düşme Riski Ölçeği Sonuçlarının Karşılaştırılması

\begin{tabular}{|c|c|c|c|c|c|c|}
\hline \multirow[t]{3}{*}{ Özellikler } & \multicolumn{4}{|c|}{ İtaki } & \multirow{3}{*}{\multicolumn{2}{|c|}{ Test Değeri }} \\
\hline & \multicolumn{2}{|c|}{ Düşük } & \multicolumn{2}{|c|}{ Yüksek } & & \\
\hline & & & & & & \\
\hline \multicolumn{7}{|l|}{ Cinsiyet } \\
\hline Kadın & 69 & 41.1 & 86 & 52.8 & $X^{2}=4.54$ & $\mathrm{p}=0.033$ \\
\hline Erkek & 99 & 58.9 & 77 & 47.2 & & \\
\hline \multicolumn{7}{|l|}{ Fiziksel aktivite düzeyi } \\
\hline Sedanter & 146 & 86.9 & 151 & 92.6 & $X^{2}=2.950$ & $\mathrm{p}=0.086$ \\
\hline Düzenli spor & 22 & 13.1 & 12 & 7.4 & & \\
\hline \multicolumn{7}{|l|}{ KBY dışında ek hastalık varlığı } \\
\hline Evet & 165 & 98.2 & 163 & 100.0 & $X^{2}=2.937$ & $\mathrm{p}=0.087$ \\
\hline Hayır & 3 & 1.8 & 0 & 0.0 & & \\
\hline
\end{tabular}

Tablo 5. Hastaların Bazı Değişkenlere Göre Morse Düşme Riski Ölçeği Sonuçlarının Karşılaştırılması

\begin{tabular}{|c|c|c|c|c|c|c|c|c|}
\hline \multirow[t]{3}{*}{ Özellikler } & \multicolumn{6}{|c|}{ Morse } & \multirow{3}{*}{\multicolumn{2}{|c|}{ Test Değeri }} \\
\hline & \multicolumn{2}{|c|}{ Düşük } & \multicolumn{2}{|c|}{ Orta } & \multicolumn{2}{|c|}{ Yüksek } & & \\
\hline & & & & $\%$ & & & & \\
\hline \multicolumn{9}{|l|}{ Cinsiyet } \\
\hline Kadın & 96 & 41.2 & 53 & 60.9 & 6 & 54.5 & $X^{2}=10.16$ & $\mathrm{p}=0.006$ \\
\hline Erkek & 137 & 58.8 & 34 & 39.1 & 5 & 45.5 & & \\
\hline \multicolumn{9}{|l|}{ Fiziksel aktivite düzeyi } \\
\hline Sedanter & 202 & 86.7 & 84 & 96.6 & 11 & 100.0 & $X^{2}=7.980$ & $\mathrm{p}=0.019$ \\
\hline Düzenli spor & 31 & 13.3 & 3 & 3.4 & 0 & 0.0 & & \\
\hline \multicolumn{9}{|l|}{ KBY dışında ek hastalık varlığı } \\
\hline Evet & 230 & 98.7 & 87 & 100.0 & 11 & 100.0 & $X^{2}=1.273$ & $\mathrm{p}=0.529$ \\
\hline Hayır & 3 & 1.3 & 0 & 0.0 & 0 & 0.0 & & \\
\hline
\end{tabular}




\section{TARTIŞMA}

Düşmeler, sonrasında yaşanan komplikasyonlara bağlı bireyde yaşam kalitesini olumsuz etkileyen önemli morbidite ve mortalite sebebidir. Kronik böbrek yetersizliğine bağlı HD tedavisi alan bireylerde de düşmeler önemli morbidite ve mortalite nedenidir (17). Yapılan bu çalışmada HD tedavisi alan bireylerin İtaki Düşme Riski Ölçeği’ne göre yaklaşık yarısının (\%49.2) yüksek düşme riskine sahip olduğu görülürken, Morse Düşme Riski Ölçeği'ne göre bireylerin \%29.6' sının orta ve yüksek düşme riskine sahip olduğu görülmektedir. İki ölçekte de düşme riski altında olan birey sayısı azımsanmayacak ölçüdedir. Kronik böbrek yetersizliği zemininde gelişen kemik mineral yoğunluğundaki azalma ile düşmeler sonucu, yaşanan kırıklar için risk artmakta ve düşmelerin daha olumsuz sonuçları olabilmektedir (23).

Örneklemi oluşturan hastaların yaş ortalamasının 65 yaş üzerinde olduğu görülmektedir (Tablo 1). Literatürde 65 ve üzeri yaş grubunda düşmenin $\operatorname{arttığ1~ve~ileri~yaşta~olmanın~düşme~riskini~}$ arttırdığ 1 belirtilmiştir (17, 24-26). Yapılan bu çalışmada yaş gruplarına göre düşme riskleri incelendiğinde de düşme riski yüksek olan gruplarda ileri yaşlı bireylerin sayısının fazla olduğu görülmektedir. $\mathrm{Bu}$ durum literatür ile uyumludur. Düşmeler açısından kadın cinsiyet de bir diğer risk faktörüdür. Bu çalışmada düşme açısından orta ve yüksek riskli gruplarda kadınların daha fazla oranda olduğu saptanmıştır (Tablo 4, 5). Özden ve arkadaşları tarafından (2012) nöroloji ve nöroşirurji kliniklerinde tedavi gören hastalarla yapılan bir çalışmada da benzer olarak düşen hastaların yarısından fazlasının kadın olduğu ifade edilmiştir (27). Ancak, Çeçen ve Özbayır'ın (2011) cerrahi kliniklerde yatan yaşlı hastaların düşme risklerini belirledikleri çalışmada cinsiyetin düşme riski ile ilişkisinin olmadığ belirtilmiştir (28).

Kesitsel olarak yapılan bu çalışmada, araştırmanın yapıldığ taların düşme risklerinin olduğu görülmektedir. $\mathrm{Bu}$ nedenle, hemşirelerin düşme risk belirleme araçları yardımı ile düşme riski olan HD hastalarını belirlemesi önemlidir. Bu çalışmadan elde edilen sonuçlara göre, her iki düşme riski belirleme ölçeğinde de düşme riski olan hastaların belirlenebildiği saptanmıştır. Ancak, Morse Düşme Riski Ölçeği'nde hastaların çoğunun düşük risk grubunda olduğu görülürken, İtaki Düşme Riski Ölçeği'ne göre hastaların yaklaşık yarısının yüksek risk grubunda olduğu görülmüştür. Bu dikkat çekicidir. Tablo 1'de görüldüğü üzere HD tedavisi alan hastaların neredeyse tamamının kronik böbrek yetmezliğine bağlı ek kronik bir hastalığının olduğu ve HD tedavisi dışında ek tedavi aldığ 1 da görülmüştür. Hemodiyaliz tedavisi dışında ek ilaç kullanımı gibi durumlar hastaların mevcut düşme riskini arttırabilmektedir. Tablo 4 ve 5 'te KBY dışında ek bir hastalığının olması durumunun düşme riskine etkisine bakılmış, ancak anlamlı bir sonuç elde edilememiştir. Bunun hastaların tamamına yak1nının ek hastalığa sahip olmasından kaynaklanabileceği düşünülmektedir. Literatürde, yaşlılık ve yaşın ilerlemesiyle birlikte meydana gelen bazı fizyolojik değişiklikler ve kronik hastalıkların düşme riskini arttırdığ 1 belirtilmektedir $(24,27$, 29). Düşme nedenlerinin incelendiği bir çalışmada ise; ileri yaş, fonksiyonel kapasitedeki azalma, diyabet varlığı ve çoklu ilaç kullanımı gibi durumların önemli etkenler olduğu bildirilmiştir (30).

Fiziksel aktivite düzeyi ile Morse Düşme Riski Ölçeği'nin incelendiği Tablo 5'te istatistiksel olarak anlamlı bir farka rastlanmıştır. Düşük riske sahip hastalar arasında daha fazla sayıda düzenli spor yapan birey olduğu görülmektedir. Duray ve Genç (2013) tarafından yapılan bir çalışmada yüksek fiziksel aktivite düzeyinin fiziksel uygunluk ve dinamik dengeyi geliştirdiği, ancak düşme riski ve düşme korkusu üzerinde etkisinin olmadığ1 belirtilmiştir (31). Literatürde düşmelerin önlenmesinde egzersiz programlarının etkinliği gösterilmiş ve fiziksel aktivitenin düşme korkusunu azalttı̆̆ belirtilmiştir $(32,33)$.

\section{SONUÇ}

Hemodiyaliz tedavisi alan hastaların İtaki Düşme Riski Ölçeği'ne göre yaklaşık yarısında düşme riski yüksek iken, Morse Düşme Riski Ölçeği'ne göre ise hastaların çoğunluğunun düşük risk grubunda olduğu görülmektedir. Her iki ölçekte ortak nokta ise kadınların erkeklere göre daha 
yüksek düşme riskine sahip olduğudur. Kliniklerde düşme risk belirleme araçlarını etkin kullanmak riskli hastaları belirlemede önemlidir. Hemodiyaliz tedavisi alan hasta grubunda daha uzun süreli, geniş hasta grubu ve farklı ölçüm araçları ile düșme riskinin ve düşme durumlarının incelendiği çalışmaların yapılması önerilmektedir.

\section{Kaynaklar}

1. Collins AJ, Foley RN, Herzog C, Chavers B, Gilbertson D et al. US Renal data system 2012 annual data report. Am J Kidney Dis 2013; 61(7): 1-476.

2. Sathvik BS, Parthasarathi G, Narahari MG, Gurudev KC. An assessment of the quality of life in hemodialysis patients using theWHOQOL-BREF questionnaire. Indian J Nephrol 2008; 18: 141-9.

3. Theofilou P. Quality of life in patients undergoing hemodialysis or peritoneal dialysis treatment. J Clin Med Res 2011; 3: $132-8$.

4. Akyol A. Hemodiyaliz hastalarında yaşam kalitesini etkileyen faktörlerin incelenmesi, Nefroloji Hemşireliği Dergisi 2016; 1: 17-33.

5. Li M, Tomlinson G, Naglie G, Cook WL, Jassal SV. Geriatric comorbidities, such as falls, confer an independent mortality riskto elderly dialysis patients. Nephrol Dial Transplant 2008; 23: 1396-400.

6. Abdel-Rahman EM, Yan G, Turgut F, Balogun RA. Longterm morbidity and mortality related to falls in hemodialysis patients: Role of age and gender-a pilot study. Nephron Clin Pract 2011; 118: 278-84.

7. Cook WL, Jassal SV. Prevalence of falls among seniors maintained on hemodialysis. Int Urol Nephrol 2005; 37: 649-52.

8. Roberts R, Jeffrey C, Carlisle G, Brierley E. Prospective investigation of the incidence of falls, dizziness and syncope in haemodialysis patients. Int Urol Nephrol 2007; 39: 275-9.

9. Injury Prevention: Falls http://www.child-encyclopedia.com/sites/default/files/textes-experts/en/819/injury-preventionfalls.pdf Erişim tarihi: 15.07.2020.

10. The Joint Commission. Preventing falls and fall-related injuries in health care facilities. Sentinel Event Alert. 2015; 55: 3. http://www.jointcommission.org/sea_issue_55/.

11. Dunne TJ, Gaboury I, Ashe MC. Falls in hospital increase length of stay regardless of degree of harm. J Eval Clin Pract 2014; 20(4): 396-400.

12. Baris VK, Intepeler SS, Yeginboy EY. The cost of serious patient fall-related injuries at hospitals in Turkey: A matched case-control study. Clin Nurs Res 2016; 29.

13. Townsend AB, Valle-Ortiz M, Sansweet T. A successful ED fall risk program using the KINDER 1 Fall Risk Assessment Tool. J Emerg Nurs. 2016; 42(6): 492-497.

14. Morley JE. Falls in elderly patients with kidney disease. J Am Soc Nephrol 2009. http:// www.asnonline.org/education_and_meetings/geriatrics/Chapter33.pdf. Erişim tarihi: 12.07.2020.

15. Roberts R, Jeffrey C, Carlisle G, Brierly E. Prospective investigation of the incidence of falls, dizziness and syncop in haemodialysis patients. Int Urol Nephrol 2007; 39(1): 275-9.

16. Çapacı K. İnmede düşme ve kırıklar. Türk Fizik Tıp Rehabilitasyon Dergisi 2007; 53: 7-10.

17. Dedeli Ö, Çınar Pakyüz S. Yaşlı diyaliz hastalarında düşmeler. Nefroloji Hemşireliği Dergisi 2015; 10 (1): 60-7.

18. Papakonstantinopoulou K, Sofianos L. Risk of falls in chronic kidney disease. Journal of Frailty, Sarcopenia and Falls JFSF 2017; 2(2): 33-38.

19. İtaki Düşme Riski Ölçeği. T.C. Sağlık Bakanlığı Resmi Web Sitesi. Erişim: http://www.kalite.saglik.gov.tr/ yazdir?402612BF1DAE9DDFAA2E4CDAF8FA155B Erişim tarihi:15.01.2019.

20. Morse JM. Preventing patient falls. 1st ed. London: SAGE Publications 1997; 85-97.

21. Morse JM. Preventing patient falls. 2nd ed. New York: Springer Publishing Company 2009; 53-9.

22. Yılmaz-Demir, N. Morse Düşme Ölçeği'nin Türkçeye uyarlanması ve duyarlılık-seçicilik düzeyinin belirlenmesi. Dokuz Eylül Üniversitesi Sağlık Bilimleri Enstitüsü Hemşirelikte Yönetim Yüksek Lisans Programı Yüksek Lisans Tezi, İzmir. 2011.

23. Broe KE, Chen TC, Weinberg J et al. A higher dose of vitamin D reduces the risk of falls in nursing home residents: a randomized, multipledose study. J Am Geriatr Soc 2007; 55: 234-9 
24. Berke D, Aslan FE. Cerrahi hastalarını bekleyen bir risk: düşmeler, nedenleri ve önlemler. Anadolu Hemşirelik ve Sağlık Bilimleri Dergisi 2010; 13(4): 72-7.

25. Savcı C, Kaya H, Acaroğlu R et al. Nöroloji ve nöroşirurji kliniklerinde hastaların düşme riski ve alınan önlemlerin belirlenmesi. Maltepe Üniversitesi Hemşirelik Bilim ve Sanatı Dergisi 2009; 2: 19-25.

26. Choi H, Trent R, Nishita C, Pynoos J. "Falls Among Older Adults in California: Public Health Surveillance Issues".www. stopfalls.org.2007 Erişim tarihi: 27.06.2020.

27. Özden D, Karagözoğlu Ş, Kurukız S. Hastaların iki ölçeğe göre düşme riskinin belirlenmesi ve bu ölçeklerin düşmeyi belirlemedeki duyarlılığı: Pilot çalışma. Anadolu Hemşirelik ve Sağlık Bilimleri Dergisi 2012; 15(1): 80-8.

28. Çeçen D, Özbayır T. Cerrahi kliniklerinde yatan yaşlı hastalarda düşme riskinin belirlenmesi ve düşmeyi önlemeye yönelik yapılan girişimlerin değerlendirilmesi. Ege Üniversitesi Hemşirelik Yüksek Okulu Dergisi, 2011; 27: 11-23.

29. Naharcı Mİ, Doruk H. Yaşlı popülasyonda düşmeye yaklaşım. TAF Preventive Medicine Bulletin 2009; 8(5): 437-44.

30. Desmet C, Beguin C, Swine C, Jadoul M. Falls in hemodialysis patients: prospective study of incidence, risk factors, and complications. Am J Kidney Dis 2005; 45: 148-53.

31. Duray M, Genç A. Farklı fiziksel aktivite düzeyine sahip olan yaşlılarda fiziksel uygunluk, düşme riski ve düşme korkusu ilişkisinin incelenmesi. DEÜ Sağlık Bilimleri Enstitüsü Nörolojik Fizyoterapi-Rehabilitasyon Yüksek Lisans Programı Yüksek Lisans Tezi, İzmir. 2013.

32. Grundstrom AC, Guse CE, Layde PM. Risk factors for falls and fall-related injuries in adults 85 years of age and older. Arc Gerontol and Geriatr 2012; 54: 421-8.

33. Yoo EJ, Jun TW, Hawkins SA. The effects of a walking exercise program on fall-related fitness, bone metabolism, and fall-related psychological factors in elderly women. Res Sports Med 2010; 18: 236-50. 